\title{
Assessment of therapeutic strategies for management of impulse control disorder in Parkinson's disease
}

\author{
Evaluación de las estrategias terapéuticas en trastornos del control de impulsos en \\ enfermedad de Parkinson \\ Mayela RODRIGGUEZ-VIOLANTE ${ }^{1,2}$, Yazmin RIOS-SOLIS', Oscar ESQUIVEL-ZAPATA ${ }^{1}$, Fanny HERRERA',2, \\ Susana LÓPEZ-ALAMILLO', Cynthia SARABIA-TAPIA', Amin CERVANTES-ARRIAGA ${ }^{1,2}$
}

\begin{abstract}
Background: Impulse control disorders (ICD) occur frequently in individuals with Parkinson's disease. So far, prevention is the best treatment. Several strategies for its treatment have been suggested, but their frequency of use and benefit have scarcely been explored. Objective: To investigate which strategy is the most commonly used in a real-life setting and its rate of response. Methods: A longitudinal study was conducted. At the baseline evaluation, data on current treatment and ICD status according to QUIP-RS were collected. The treatment strategies were categorized as "no-change", dopamine agonist (DA) dose lowering, DA removal, DA switch or add-on therapy. At the six-month follow-up visit, the same tools were applied. Results: A total of 132 individuals (58.3\% men) were included; $18.2 \%$ had at least one ICD at baseline. The therapeutic strategy most used in the ICD group was no-change (37.5\%), followed by DA removal (16.7\%), DA switch (12.5\%) and DA lowering (8.3\%). Unexpectedly, in $20.8 \%$ of the ICD subjects the DA dose was increased. Overall, nearly $80 \%$ of the subjects showed remission of their ICD at follow-up. Conclusions: Regardless of the therapy used, most of the subjects presented remission of their ICD at follow-up Further research with a longer follow-up in a larger sample, with assessment of decision-making processes, is required in order to better understand the efficacy of strategies for ICD treatment.
\end{abstract}

Keywords: Parkinson Disease; Disruptive, Impulse Control, and Conduct Disorders; Treatment Outcome.

\section{RESUMEN}

Antecedentes: Los trastornos del control de impulsos (TCl) son frecuentes en personas con enfermedad de Parkinson. A la fecha, la prevención es el mejor tratamiento. Existen varias estrategias sugeridas para su tratamiento, pero su frecuencia de uso y beneficio ha sido escasamente explorada. Objetivo: Investigar qué estrategia es la más utilizada en un entorno de la vida real y su tasa de respuesta. Métodos: Se realizó un estudio longitudinal. En la evaluación inicial, se recopiló el tratamiento actual y el estado del TCI de acuerdo con el QUIP-RS. La estrategia de tratamiento se clasificó como "sin cambios", reducción de la dosis de agonista de la dopamina (AD), eliminación de AD, cambio de AD o terapia complementaria. En la visita de seguimiento a los 6 meses, se aplicaron las mismas herramientas. Resultados: Se incluyeron un total de 132 (58.3\% hombres) personas. El 18.2\% tenía al menos un TCl al inicio del estudio. La estrategia terapéutica más utilizada en el grupo de TCl fue sin cambios (37.5\%), seguida de eliminación de DA (16.7\%), cambio de AD (12.5\%) y reducción de DA (8.3\%). En el 20.8\% de los sujetos con TCl se aumentó la dosis de AD. Casi el $80 \%$ de los sujetos tuvieron una remisión del TCl al seguimiento. Conclusiones: Independientemente de la terapia utilizada, la mayoría de los sujetos tuvieron una remisión del TCl. Se requiere más investigación con un seguimiento y una muestra mayor para evaluar I proceso de toma de decisiones para comprender mejor la eficacia de las estrategias.

Palabras clave: Enfermedad de Parkinson; Trastornos Disruptivos, del Control de Impulso y de la Conducta; Resultado del Tratamiento.

\section{INTRODUCTION}

Parkinson's disease (PD) is a common adult-onset neurodegenerative disease characterized by relatively selective loss of neuronal subtypes, notably those of the nigrostriatal dopaminergic pathway ${ }^{1}$. PD is characterized by motor symptomatology, including bradykinesia, rigidity, postural instability and resting tremor. On the other hand, PD is also accompanied by

\footnotetext{
${ }^{1}$ National Institute of Neurology and Neurosurgery, Clinical Neurodegenerative Research Unit, Mexico City, Mexico.

${ }^{2}$ National Institute of Neurology and Neurosurgery, Movement Disorder Clinic, Mexico City, Mexico.

MRV (D) https://orcid.org/0000-0002-6041-9941; YRS (D) https://orcid.org/0000-0003-3193-0086; OEZ (D) https://orcid.org/0000-0002-6647-7536; FH (iD https://orcid.org/0000-0003-1508-5097; SLA (iD) https://orcid.org/0000-0001-6428-547X; CST (iD https://orcid.org/0000-0002-3055-1546;

ACA (iD) https://orcid.org/0000-0002-3935-9278

Correspondence:Amin Cervantes-Arriaga; Email:acervantes@innn.edu.mx.

Conflict of interest: There is no conflict of interest to declare.
}

Authors' contributions: FH, YRS, SLA, CST: data acquisition; MRV, FH, YRS: study conception and design; OEZ, ACA: data analysis and interpretation; MRV, YRS, OEZ, ACA: drafting, reviewing and final approval of the manuscript.

Received on October 26, 2020; Received in its final form on December 22, 2020; Accepted on January 13, 2021. 
a myriad of nonmotor manifestations, including cognitive and neuropsychiatric disorders ${ }^{2}$. Impulse control disorders (ICDs) are defined as a group of disorders characterized by behavioral disinhibition including pathological gambling, compulsive shopping, hypersexuality and binge eating. Other related disorders, such as dopaminergic dysregulation syndrome (DDS), punding and hobbyism are also considered to form of the clinical spectrum ${ }^{3,4}$.

ICDs have been reported to occur in $3.5 \%$ to $42.8 \%$ of individuals with $\mathrm{PD}$, depending on the study population and methodology; moreover, up to $29 \%$ of the patients suffer more than one type of $\mathrm{ICD}^{5-8}$.

ICDs in PD have been associated with dopaminergic therapy, younger age at PD onset, smoking history, personal or family history of alcohol abuse, greater novelty-seeking behavior, impulsivity and depressed $\operatorname{mood}^{9}$. In addition, genetic factors, such as DOPA decarboxylase gene polymorphisms, may also play a role in the risk of ICD development ${ }^{10}$.

These disorders usually occur without the patient being aware of the symptoms ${ }^{11}$. However, ICDs can lead to severe consequences, including major financial loss, bankruptcy, disrupted social relationships, divorce, institutionalization and legal problems, with a great impact on the quality of life (QoL) of these patients and increased caregiver distress ${ }^{12-14}$.

So far, the best treatment is preemption and prevention. The strategies that have been suggested include switching the dopamine agonist (DA), tapering down or discontinuing the DA, use of atypical antipsychotics such as quetiapine or clozapine, cognitive behavioral therapy and deep brain stimulation ${ }^{15,16}$. Currently, there is no consensus or guidelines on which therapeutic strategy is more effective. Evidence on the frequency of use and efficacy of each strategy is scarce.

The objective of this study was to determine which therapeutic strategy is the most frequently used for management of ICDs in a real-life PD sample and to assess its rate of response.

\section{METHODS}

A longitudinal study among consecutive patients with a clinical diagnosis of PD in accordance with the Movement Disorder Society clinical diagnostic criteria was conducted ${ }^{17}$. These patients attended the outpatient clinic of the Movement Disorder Clinic of the National Institute of Neurology and Neurosurgery between September 2014 and August 2019. Only patients who had a baseline visit and a follow-up visit at $6 \pm 1$ months were included.

Demographic data including age and sex were collected. The clinical data collected included disease duration, antiparkinsonian drug use and daily dose of levodopa equivalents (LEDD) ${ }^{18}$.

At each visit, the following clinical tools were applied by a neurologist with expertise in movement disorders.

The Movement Disorder Society Unified Parkinson's Disease Scale(MDS-UPDRS), which comprises four parts, was used. Part I evaluates non-motor experiences of daily life (0-52 points); part II assesses motor experiences of daily life (0-52 points); part III comprises a motor examination (0-108 points); and part IV assesses motor complications (0-24 points) ${ }^{19}$.

The Hoehn and Yahr scale was used to classify subjects with PD according to the severity of their symptoms ${ }^{20}$. Subjects were classified as presenting mild (stages 1 and 2), moderate (stage 3 ) or severe disease (stages 4 and 5).

Non-motor symptoms were assessed using the Non-motor Symptoms Scale (NMSS). The NMSS has 30 items divided into nine domains and allows non-motor symptomatology to be graded through inclusion of frequency and severity. The domains include cardiovascular, sleep/fatigue, mood/cognition, perception/hallucinations, attention/memory, gastrointestinal, urinary, sexual and miscellaneous. For each item, a severity rating (from 0 to 3 ) and a frequency rating ( 1 to 4 ) are obtained; these two variables are multiplied together to obtain the total value ${ }^{21}$

Disease-related quality of life was assessed using the PD Quality of Life Questionnaire (PDQ-8). The PDQ-8 is a diseasespecific instrument that assesses eight aspects of health-related quality of life. The domains evaluated are mobility, activities of daily living, emotional wellbeing, stigma, social support, cognition, communication and bodily discomfort. Each item is scored on a Likert-type scale and the total score is transformed into a simplified index (range from 0 to 100) that indicates the degree of overall condition in relation to the patient's quality of life. Values closer to zero indicate better quality of life (PDQ8-SI) ${ }^{22}$.

Lastly, the presence of ICDs was assessed using the Questionnaire for Impulsive-Compulsive Disorders in Parkinson's Disease (QUIP-RS). The QUIP-RS is composed of four main questions (relating to frequent thoughts, desires and behaviors associated with impulse control disorder), each applied to the main symptoms of impulse control disorder (gambling, excessive shopping, hypersexuality and compulsive eating) and related disorders (DDS, punding and hobbyism). A five-point Likert scale (score of 0-4 for each question) is used to measure the frequency of behaviors that have occurred in the last four weeks. The total score ranges from 0 to 112 . The following cutoff values for each symptom were used: gambling $\geq 6$, compulsive shopping $\geq 8$, hypersexuality $\geq 8$, binge eating $\geq 7$ and hobbies/punding $\geq 7^{23}$.

For the purposes of the present study, the subjects were classified according to the presence of ICD (non-ICD-PD or ICD-PD).

The therapeutic strategy undertaken in the ICD-PD group was recorded and classified as follows. Subjects who remained under the same drug and dose were deemed to be "no-change". Changes to the dopamine agonist treatment were classified as DA dose lowering or as DA removal. DA switch was defined as replacing an immediate-release DA for an extended-release formulation or changing from an oral to a transdermal formulation. Use of a new drug, such as an antipsychotic or amantadine, was considered to be add-on therapy. Use of non-pharmacological 
treatment, including cognitive behavioral therapy and deep brain stimulation, was also recorded.

At the follow-up visit, the same clinical tools were applied by the same rater. The success rate for each strategy was defined as the percentage of subjects with ICD at baseline who did not have ICD at the follow-up visit.

This study was approved by the local ethics committee. Signed informed consent was obtained from all the participants.

\section{Statistical analysis}

The Shapiro-Wilk test was used to assess normality. Quantitative variables were compared between groups using Student's t test or the Mann-Whitney U test, as needed. Qualitative variables were compared between groups using the chi-square test.

Quantitative variables were compared between the baseline and follow-up visits using a paired t test or the Wilcoxon test, as needed. The McNemar test was used for comparison of qualitative variables between visits. P-values $<0.05$ were considered statistically significant. The statistical analyses were performed using SPSS, v.17 (SPSS Inc., Chicago, IL, USA.)

\section{RESULTS}

\section{Baseline visit}

A total of 55 women (41.7\%) and 77 men (58.3\%) were included. The mean age at the baseline visit was $61.9 \pm 11.9$ years. The mean disease duration was $7.4 \pm 5.7$ years.

The mean total QUIP-RS score at baseline was $4.5 \pm 8.3$. A total of 108 subjects $(81.8 \%$ ) did not have ICD, while $24(18.2 \%)$ had at least one ICD. All subjects with ICD were medicated with a DA (six on rotigotine and the remainder on immediaterelease pramipexole).
Table 1 compares the main demographic and clinical variables between groups. In summary, no statistically significant differences were found regarding sex and age at onset. Subjects in the ICD-PD group had higher DA-LEDD, total LEDD and MDS-UPDRS I, II and IV, in comparison with the non-ICD-PD group. Also, the total NMSS score was higher in the ICD-PD group. After analyzing individual NMSS domains, only the perceptual problems/hallucinations domain was found to be higher in the ICD-PD group $(2.3 \pm 4.6$ vs $0.5 \pm 1.6$; $\mathrm{p}=0.034)$. Subjects in the ICD-PD group had worse quality of life, compared with the non-ICD patients.

The ICD-PD group had a median of one ICD (range 1-3). There were 15 subjects $(62.5 \%)$ with only one ICD, while $37.5 \%$ had multiple ICDs (8.3\% had at least three different ICDs).

Regarding individual ICDs, compulsive eating was found in $45.8 \%$, hobbyism in $45.8 \%$, punding in $25 \%$, compulsive shopping in $8.3 \%$ and hypersexuality in $4.2 \%$. Pathological gambling was not found in any subject.

The therapeutic strategy most used in the ICD-PD group was no-change (37.5\%), followed by DA removal (16.7\%), DA switch (12.5\%) and DA lowering (8.3\%). Unexpectedly, in $20.8 \%$ of the ICD-PD subjects, the DA dose was increased. Antipsychotics, cognitive behavioral therapy and deep brain stimulation strategies were not used in any subject.

\section{Follow-up visit}

At the follow-up visit, $79.2 \%$ of the subjects in the ICD-PD groups showed remission of the ICD, regardless of the strategy used. Consequently, a decrease in the mean total QUIP-RS score in the ICD-PD group was found $(18 \pm 11$ vs $4.2 \pm 7.2 ; \mathrm{p}$ $<0.001$ ). Conversely, $7.4 \%$ of the subjects initially in the nonICD-PD patients were found to have developed an ICD at the

Table 1. Comparison of main variables between subjects in the non-ICD-PD and ICD-PD groups at baseline.

\begin{tabular}{|c|c|c|c|c|}
\hline & & Non-ICD-PD & ICD-PD & $\mathrm{p}$ \\
\hline & & $n=108$ & $n=24$ & \\
\hline \multicolumn{2}{|l|}{ Age (years) } & $62.8 \pm 11.9$ & $57.8 \pm 11.1$ & 0.06 \\
\hline \multicolumn{2}{|l|}{ Male (\%) } & 66 (61.1\%) & $11(45.8 \%)$ & 0.17 \\
\hline \multicolumn{2}{|l|}{ DA-LEDD (mg) } & $152.6 \pm 152.4$ & $237.9 \pm 143.9$ & 0.014 \\
\hline \multicolumn{2}{|l|}{ Total LEDD (mg) } & $167.4 \pm 162.5$ & $290 \pm 174.3$ & 0.003 \\
\hline \multirow[t]{5}{*}{ MDS-UPDRS } & & $49.1 \pm 20.1$ & $64.8 \pm 28.7$ & 0.008 \\
\hline & Part I & $8.5 \pm 5.5$ & $11.9 \pm 5.5$ & 0.005 \\
\hline & Part II & $11.7 \pm 8$ & $18.3 \pm 10.7$ & 0.003 \\
\hline & Part III & $27.8 \pm 12.4$ & $31.7 \pm 15.5$ & 0.31 \\
\hline & Part IV & $1.1 \pm 2.4$ & $2.8 \pm 3.4$ & 0.001 \\
\hline \multicolumn{2}{|l|}{ QUIP-RS } & $1.44 \pm 2.7$ & $17.96 \pm 11.01$ & $<0.001$ \\
\hline \multicolumn{2}{|l|}{ NMSS } & $41.84 \pm 39.1$ & $55.5 \pm 41.7$ & 0.03 \\
\hline \multicolumn{2}{|l|}{ PDQ8-SI } & $21.55 \pm 18.9$ & $36.58 \pm 24.7$ & 0.001 \\
\hline
\end{tabular}

DA: dopamine agonist; LEDD: levodopa equivalent daily dose; MDS-UPDRS: Movement Disorder Society Unified Parkinson Disease Rating Scale; QUIP-RS: Questionnaire for Impulsive-Compulsive Disorders Rating Scale; NMSS: Non-Motor Symptoms Scale; PDQ8-SI: Parkinson's Disease Questionnaire Summary Index; ICD: impulse control disorder; PD: Parkinson's disease. 
follow-up. No difference in MDS-UPDRS III was found at the follow-up, in comparison with the baseline score.

No-change was the most frequent and the most effective strategy with a remission rate of $100 \%$, followed by discontinuing the DA with an effectiveness of $75 \%$. Increasing the DA dose had a success rate of $60 \%$, which was higher than the rate through lowering DA strategy and similar to switching DA. Table 2 summarizes the therapeutic strategies and their outcomes, and the changes to MDS-UPDRS III and QUIP-RS scores. Overall, only the no-change strategy resulted in a statistically significant improvement in MDS-UPDRS III at follow-up (mean difference of 4.5; 95\% CI 3.03-23.6).

Table 2. Therapeutic strategies, MDS-UPDRS part III and QUIP-RS score among subjects with ICD-PD.

\begin{tabular}{|c|c|c|c|c|c|c|c|c|c|}
\hline \multirow[t]{2}{*}{$\begin{array}{l}\text { Therapeutic } \\
\text { strategy }\end{array}$} & \multirow[t]{2}{*}{$\mathrm{N}$} & \multirow[t]{2}{*}{$\begin{array}{l}\text { Subjects with } \\
\text { ICD remission }\end{array}$} & \multirow[t]{2}{*}{$\begin{array}{l}\text { Subject } \\
\text { with ICD }\end{array}$} & \multicolumn{3}{|c|}{ MDS-UPDRS part III } & \multicolumn{3}{|c|}{ QUIP-RS score } \\
\hline & & & & $\begin{array}{c}\text { Baseline } \\
\text { visit }\end{array}$ & $\begin{array}{l}\text { Follow-up } \\
\text { visit }\end{array}$ & $p$ & $\begin{array}{l}\text { Baseline } \\
\text { visit }\end{array}$ & $\begin{array}{l}\text { Follow-up } \\
\text { visit }\end{array}$ & $p$ \\
\hline ICD-PD & 24 & $19(79.2 \%)$ & $5(20.8 \%)$ & $31.7 \pm 15.5$ & $28 \pm 12.8$ & 0.281 & $18 \pm 11$ & $4.2 \pm 7.2$ & $<0.001$ \\
\hline No change & $9(37.5 \%)$ & $9(100 \%)$ & 0 & $24.1 \pm 7.6$ & $24.3 \pm 7.1$ & 0.735 & $\begin{array}{c}14.4 \pm \\
13.1\end{array}$ & $1.1 \pm 2.1$ & 0.01 \\
\hline DA discontinuation & $4(16.7 \%)$ & $3(75 \%)$ & $1(25 \%)$ & $43 \pm 8.1$ & $32.5 \pm 14.4$ & 0.109 & $15.5 \pm 8.6$ & $2.3 \pm 4.5$ & 0.07 \\
\hline DA switch & $3(12.5 \%)$ & $2(66.7 \%)$ & $1(33.3 \%)$ & $33.3 \pm 26.4$ & $32.3 \pm 28$ & 0.276 & $19.7 \pm 5.7$ & $4 \pm 9.7$ & 0.11 \\
\hline DA lowering & $2(8.3 \%)$ & $1(50 \%)$ & $1(50 \%)$ & $35 \pm 4.2$ & $27 \pm 5.6$ & 0.180 & $25.5 \pm 7.8$ & $11.5 \pm 7.8$ & 0.18 \\
\hline DA increase & $5(20.8 \%)$ & $3(60 \%)$ & $2(40 \%)$ & $25 \pm 5.7$ & $26 \pm 13$ & 0.686 & $\begin{array}{c}24.2 \pm \\
11.3\end{array}$ & $9.4 \pm 11.9$ & 0.08 \\
\hline DA add-on & $1(4.2 \%)$ & $1(100 \%)$ & 0 & 77 & 41 & 0.317 & 8 & 0 & - \\
\hline
\end{tabular}

DA: dopamine agonist; MDS-UPDRS: Movement Disorder Society Unified Parkinson's Disease Rating Scale; QUIP-RS: Questionnaire for Impulsive-Compulsive Disorders Rating Scale; ICD: impulse control disorder; PD: Parkinson's disease.

\section{DISCUSSION}

The prevalence of ICD and related disorders in Mexican PD subjects has been reported to be $25.6 \%^{24}$; in this study, the prevalence was lower, at $18.2 \%$. Regarding risk factors for ICD, DA-LEDD and the total LEDD were higher in the ICD-PD group. On the other hand, our study did not find any difference between the groups regarding age or sex. In the case of age, a trend was present but did not reach statistical significance.

Level I evidence on the management of ICD in PD is still lacking; nevertheless, several strategies have been recommended ${ }^{25}$. Since it has been reported that DA treatment in PD is associated with 2 to 3.5-fold increased odds of having an $\mathrm{ICD}^{6}$, the three main approaches include lowering, switching or discontinuing the DA. In our study sample, DA-centered strategies were used for $37.5 \%$ of the ICD-PD subjects; the combined remission rate was $66.7 \%$. Nonetheless, the most frequently used therapeutic strategy among ICD-PD subjects was no-change. Regardless of the number of ICD domains affected or the total QUIP-RS score, all subjects managed with this strategy were free from ICD at the follow-up, with no significant change in MDS-UPDRS III.

In the present study, the most striking finding was that in $20.8 \%$ of the subjects with ICD, the DA dose was in fact increased. In three out of the five subjects, the ICD remitted. Unfortunately, this study was not designed to assess the decision-making process. Nonetheless, it can be hypothesized that this strategy might be influenced by a trade-off between ICD severity and possible motor benefit.
Several studies have reported relatively high remission rates ranging from $30 \%$ to $48.6 \%$, regardless of the strategy used among the patients ${ }^{5,26}$. It is worth mentioning that those studies were not designed to identify either the strategy used to treat the ICD or the efficacy of the different approaches. Notwithstanding this, the evidence suggests that regardless of the approach used, a large percentage of PD subjects with ICD would achieve resolution of the disorder at a follow-up visit. In most cases, the decision on the strategy should be individualized. For example, the no-change group in our study had a stable score in MDS-UPDRS III and a relatively low score in QUIP-RS, which could have been the main reason for the decision not to change the pharmacological treatment. In other words, the patient's ON state can be prioritized when the ICD does not represent a great disturbance for the patient or does not affect the daily living activities or quality of life. On the other hand, it is very important to consider that patients may underestimate the presence and severity of ICDs, or the impact on their family and caregivers ${ }^{27}$.

Few factors associated with ICD remission or persistence, other than DA treatment, have been reported. Better performance in working memory-related tasks at baseline has been associated with remission ${ }^{28}$, although cognitive changes over time do not differ between patients with and without ICD $^{29}$. Conversely, younger age and personality traits such as higher levels of anger expression and obsessive-compulsive behaviors have been associated with refractory ICD ${ }^{30,31}$. These variables may also play a role in the high overall rate of remission of ICD 
that is seen in PD. Unfortunately, the small sample size and the lack of formal cognitive and personality trait assessments in our study did not allow further analysis on this matter.

Some limitations regarding our study can be listed. First, as mentioned earlier, the factors that contributed to the decisionmaking by the neurologist were not assessed. Further investigations to address this issue are needed, including the role of shared decision-making. Another limitation was the relatively low prevalence of the ICDs: even though in our sample the prevalence was higher than in some other reports, each strategy group was formed by only a small number of subjects. Studies with larger samples are needed, to confirm our findings. Also, it has been reported that ICDs tend to have a slower risk evolution pattern as the disease progresses ${ }^{32}$; while the disease duration in our study sample was similar to what had previously been seen in other large studies, our findings might not be generalizable to subjects with shorter disease durations.

Lastly, the follow-up included only one additional visit and, thus, relapse could not be assessed. On this matter, the ICARUS study found that there was relatively stable prevalence of ICDs during its two-year follow-up $\mathrm{p}^{33}$. In our study sample, the incidence was around $7 \%$ at six months, so it might be expected that a longer follow-up would result in higher numbers of cases. It should be pointed out that ICD relapse has scarcely been reported. Erga et al. ${ }^{29}$ reported that their relapse rate was $3.7 \%(\mathrm{n}=82)$ over a four-year follow-up; in contrast, the DIGPD study ${ }^{26}$ reported a relapse rate of $31.7 \%(n=85)$, also after a four-year follow-up.

Therefore, further research with a longer follow-up in a larger sample assessing the factors that neurologists considered in the decision-making process is required, to better understand the efficacy of the strategies in the ICDs treatment.

In conclusion, the most frequent and effective therapeutic strategy used in this longitudinal study of subjects with ICD-PD was not to make any changes; but regardless of the strategy, almost $80 \%$ showed remission at a six-month follow-up.

\section{REFERENCES}

1. Armstrong MJ, Okun MS. Diagnosis and treatment of Parkinson Disease: a review. JAMA. 2020 Feb 11;323(6):548-60. hhttps://doi. org/10.1001/jama.2019.22360

2. Schapira AHV, Chaudhuri KR, Jenner P. Non-motor features of Parkinson disease. Nat Rev Neurosci. 2017 Jul;18(7):435-50. https:// doi.org/10.1038/nrn.2017.62

3. Molde H, Moussavi Y, Kopperud ST, Erga AH, Hansen AL, Pallesen S. Impulse-Control disorders in Parkinson's Disease: a meta-analysis and review of case-control studies. Front Neurol. 2018 May 22;9:330. https://doi.org/10.3389/fneur.2018.00330

4. Voon V, Sohr M, Lang AE, Potenza MN, Siderowf AD, Whetteckey J, et al. Impulse control disorders in Parkinson disease: a multicenter case--control study. Ann Neurol. 2011 Jun;69(6):986-96. https://doi. org/10.1002/ana.22356

5. Leeman RF, Potenza MN. Impulse control disorders in Parkinson's disease: clinical characteristics and implications. Neuropsychiatry (London). 2011 Apr;1(2):133-47. https://doi.org/10.2217/npy.11.11

6. Weintraub D, Koester J, Potenza MN, Siderowf AD, Stacy M, Voon V, et al. Impulse control disorders in Parkinson disease: a cross-sectional study of 3090 patients. Arch Neurol. 2010 May;67(5):589-95. https:// doi.org/10.1001/archneurol.2010.65

7. Antonini A, Barone P, Bonuccelli U, Annoni K, Asgharnejad M, Stanzione P. ICARUS study: prevalence and clinical features of impulse control disorders in Parkinson's disease. J Neurol Neurosurg Psychiatry. 2017 Apr;88(4):317-24. https://doi.org/10.1136/jnnp2016-315277

8. Marković V, Stanković I, Petrović I, Stojković T, Dragašević-Mišković N, Radovanović S, et al. Dynamics of impulsive-compulsive behaviors in early Parkinson's disease: a prospective study. J Neurol. 2020 Apr;267(4):1127-36. https://doi.org/10.1007/s00415-019-09692-4

9. Liu B, Luo W, Mo Y, Wei C, Tao R, Han M. Meta-analysis of related factors of impulse control disorders in patients with Parkinson's disease. Neurosci Lett. 2019 Aug 10;707:134313. https://doi. org/10.1016/j.neulet.2019.134313

10. Jesús S, Periñán MT, Cortés C, Buiza-Rueda D, Macías-García D, Adarmes A, et al. Integrating genetic and clinical data to predict impulse control disorders in Parkinson's disease. Eur J Neurol. 2021 Feb;28(2):459-68. https://doi.org/10.1111/ene.14590

11. Goerlich-Dobre KS, Probst C, Winter L, Witt K, Deuschl G, Möller B, et al. Alexithymia-an independent risk factor for impulsive-compulsive disorders in Parkinson's disease. Mov Disord. 2014 Feb;29(2):214-20. https://doi.org/10.1002/mds.25679

12. Ryu D-W, Kim J-S, Yoo S-W, Oh Y-S, Lee K-S. The impact of impulsivity on quality of life in early Drug-Naïve Parkinson's disease patients. J Mov Disord. 2019 Sep;12(3):172-76. https://doi.org/10.14802/ jmd.19004

13. Phu AL, Xu Z, Brakoulias V, Mahant N, Fung VS, Moore GD, et al. Effect of impulse control disorders on disability and quality of life in Parkinson's disease patients. J Clin Neurosci. 2014 Jan 1;21(1):63-6. https://doi.org/10.1016/j.jocn.2013.02.032

14. Erga AH, Alves G, Tysnes OB, Pedersen KF. Impulsive and compulsive behaviors in Parkinson's disease: impact on quality of and satisfaction with life, and caregiver burden. Parkinsonism Relat Disord. 2020 Sep;78:27-30. https://doi.org/10.1016/j. parkreldis.2020.07.007

15. Kelly MJ, Baig F, Hu MT, Okai D. Spectrum of impulse control behaviours in Parkinson's disease: pathophysiology and management. J Neurol Neurosurg Psychiatry. 2020 Jul;91(7):703-11. https://doi.org/10.1136/jnnp-2019-322453

16. Seppi K, Chaudhuri KR, Coelho M, Fox SH, Katzenschlager R, Lloret SP, et al. Update on treatments for nonmotor symptoms of Parkinson's disease-an evidence-based medicine review. Mov Disord. 2019 Feb;34(2):180-98. https://doi.org/10.1002/mds.27602

17. Postuma RB, Berg D, Stern M, Poewe W, Olanow CW, Oertel W, et al. MDS clinical diagnostic criteria for Parkinson's disease. Mov Disord. 2015 Oct;30(12):1591-601. https://doi.org/10.1002/mds.26424

18. Tomlinson CL, Stowe R, Patel S, Rick C, Gray R, Clarke CE. Systematic review of levodopa dose equivalency reporting in Parkinson's disease. Mov Disord. 2010 Nov 15;25(15):2649-53. https://doi.org/10.1002/ mds.23429

19. Martinez-Martin P, Rodriguez-Blazquez C, Alvarez-Sanchez M, Arakaki T, Bergareche-Yarza A, Chade A, et al. Expanded and independent validation of the Movement Disorder Society-Unified Parkinson's Disease Rating Scale (MDS-UPDRS). J Neurol. 2013 Jan;260(1):228-36. https://doi.org/10.1007/s00415-012-6624-1

20. Hoehn MM, Yahr MD. Parkinsonism: onset, progression and mortality. Neurology. 1967 May 1;17(5):427-42. https://doi.org/10.1212/ WNL.17.5.427 
21. Chaudhuri KR, Martinez-Martin P, Brown RG, Sethi K, Stocchi F, Odin $P$, et al. The metric properties of a novel non-motor symptoms scale for Parkinson's disease: results from an international pilot study. Mov Disord. 2007 Oct 15;22(13):1901-11. https://doi.org/10.1002/ mds.21596

22. Katsarou Z, Bostantjopoulou S, Peto V, Kafantari A, Apostolidou E, Peitsidou E. Assessing quality of life in Parkinson's disease: can a short-form questionnaire be useful? Mov Disord. 2004 Mar;19(3):308-12. https://doi.org/10.1002/mds.10678

23. Weintraub D, Mamikonyan E, Papay K, Shea JA, Xie SX, Siderowf A. Questionnaire for Impulsive-Compulsive Disorders in Parkinson's Disease-Rating scale. Mov Disord. 2012 Feb;27(2):242-7. https://doi. org/10.1002/mds. 24023

24. Rodríguez-Violante M, González-Latapi P, Cervantes-Arriaga A, Camacho-Ordoñez A, Weintraub D. Impulse control and related disorders in Mexican Parkinson's disease patients. Parkinsonism Relat Disord. 2014 Aug 1;20(8):P907-10. https://doi.org/10.1016/j. parkreldis.2014.05.014

25. Ramirez-Zamora A, Gee L, Boyd J, Biller J. Treatment of impulse control disorders in Parkinson's disease: practical considerations and future directions. Expert Rev Neurother. 2016;16(4):389-99. https:// doi.org/10.1586/14737175.2016.1158103

26. Corvol J-C, Artaud F, Cormier-Dequaire F, Rascol O, Durif F, Derkinderen P, et al. Longitudinal analysis of impulse control disorders in Parkinson disease. Neurology. 2018 Jul 17;91(3):e189-e201. https://doi.org/10.1212/ WNL.0000000000005816

27. Baumann-Vogel H, Valko PO, Eisele G, Baumann CR. Impulse control disorders in Parkinson's disease: don't set your mind at rest by self-assessments. Eur J Neurol. 2015 Apr;22(4):603-9. https://doi. org/10.1111/ene.12646

28. Siri C, Cilia R, Reali E, Pozzi B, Cereda E, Colombo A, et al. Long-term cognitive follow-up of Parkinson's disease patients with impulse control disorders. Mov Disord. 2015 Apr 15;30(5):696-704. https://doi. org/10.1002/mds. 26160

29. 29. Erga AH, Alves G, Tysnes OB, Pedersen KF. Evolution of impulsivecompulsive behaviors and cognition in Parkinson's disease. J Neurol. 2020 Jan;267(1):259-66. https://doi.org/10.1007/s00415-019-095847

30. Kon T, Ueno T, Haga R, Tomiyama M. The factors associated with impulse control behaviors in Parkinson's disease: A 2-year longitudinal retrospective cohort study. Brain Behav. 2018 Aug;8(8):e01036. https://doi.org/10.1002/brb3.1036

31. Choi J-H, Lee J-Y, Jeon B, Koh S-B, Yoon WT, Lee H-W, et al. Neuropsychiatric traits associated with refractory impulse control disorder in Parkinson's Disease. Neurodegener Dis. 2019;19(5-6):17177. https://doi.org/10.1159/000507447

32. Prange S, Danaila T, Laurencin C, Caire C, Metereau E, Merle H, et al. Age and time course of long-term motor and nonmotor complications in Parkinson disease. Neurology. 2019 Jan 8;92(2):e148-60. https:// doi.org/10.1212/WNL.0000000000006737

33. Barone P, Antonini A, Stanzione P, Annoni K, Asgharnejad M, Bonuccelli U. Risk factors for impulse control disorders and related behaviors in Parkinson's disease: secondary analyses of the ICARUS study.J Drug Assess. 2019 Oct 4;8(1):159-66. https://doi.org/10.1080/ 21556660.2019.1675670 